Epidemiology of diaheles in developing countries. New Delhi: Interprint, 1979:93-102

5 Mather HM, Keen $\mathrm{H}$. The Southall diabetes survev: prevalence of diabetes in Asians and Europeans. Br Med 7 1985;291:1081-4.

6 Ahuja MMS. Epidemiological studies on diabetes mellitus in India. In: Ahuja MMS, ed. Epidemiology of diabeles in developing countries. New Delhi: Interprint, 1979;29-38.

7 Verma NPS, Mehta SP, Madhu S, Mather HM, Keen H. Prevalence of known diabetes in an urban Indian environment: the Darya Ganj diabetes survey. diabetes in an urban Indian
Br Med $\mathcal{Y} 1986: 293: 423-4$

8 World Health Organisation. Diabetes mellitus. WHO Tech Rep Ser 1985; No 727

9 Hyvarinen A, Nikkila EA. Specific determination of blood glucose with orthotoluidine. Clin Chim Actu 1962;7:140-3.

10 Wybenga DR, Pileggi VJ, Dirstine PH, el al. Direct manual determination of serum total cholesterol with a single stable reagent. Clin Chem 1970;16 980-4.

11 Lavori PW, Louis TA, Bailar JC, Polansky M. Design for experimentsparallel comparisons of treatment. In: Bailar JC, Mosteller F, eds. Medicul uses of stutistics. Waltham, MA: Massachusetts Medical Society, 1986:41-66.

12 Hoskins PL, Handelsman DJ, Hannelly T, Silink M, Yue DK, Turtle JR. Diabetes in the Melanesian and Indian peoples of Fiji: a study of risk factors. Diabeles Res Clin Pract 1987;3:269-76. 13 Thai AC, Yeo PFB, Lun KC, et al. Changing prevalence of diabetes mellitus in

14 Ramachandran A, Gallaghar F, Mohan V, et al. Comparative study of the elinical pattern of diabetes from two referral centres for diabetes in the United States of America and India. Joumal of the Diabetic Association of India 1986;26:83-8

15 Mohan V, Ramachandran A, Viswanathan M. Tropical diabetes. In: Alberti KGMM, Krall LP, eds. The diabetes annual. Vol 2. Amsterdam: Elsevier, 1986:30-8.

16 Omar MAK, Hammond MG, Seedat MA, et al. The prevalence of diabetes mellitus in a large group of South African Indians. S Af Med 7 1985;67. $92+-6$

17 West KM. Diabetes in the tropics: some lessons for western diabetology. In Podulsky S, Viswanathan M, eds. Secondan diabetes: the spectrum of the diabetic syndromes. New York: Raven, 1980:249-55.

18 Ramachandran A, Snehalatha C, Naik RAS, Mohan V, Shobana R, Viswanathan $M$. Significance of impaired glucose tolerance in an Asian Indian population.: a follow-up study. Diabeles Res Clim Pract 1986;2:173-8.

19 Mohan V, Sharp PS, Aber VR, Mather HM, Kohner EM. Family histories of Asian and European non-insulin dependent diabetic patients. Practical Diabeles 1986;3:254-6.

20 Viswanathan M, Mohan V, Snehalatha C, Ramachandran A. High prevalence of type 2 (non-insulin dependent) diabetes among offspring of conjugal type 2 diabetic parents in India. Diabetologia 1986;28:907-10.

21 Kamachandran $A$ Mohan $V$ snchalatha $C$, Viswanathan $M$ l'revalence of non-insulin dependent diabetes mellitus in Asian Indian families with a single diabetic parent. Diabetes Res Clin Pract 1988;4:241-5.

(Accepted 5 Mav 1988)

\title{
Save the prepuce. Painless separation of preputial adhesions in the outpatient clinic
}

\author{
G A MacKinlay
}

\begin{abstract}
In most boys referred for circumcision preputial adhesions are the only problem, but these can predispose to recurrent balanitis. A simple technique using Emla cream (eutectic mixture of lignocaine and prilocaine) has been devised which allows the adhesions to be separated painlessly in the outpatient clinic. The technique was used on 39 boys aged 2 to 12 years referred for circumcision, none of whom had a retractable foreskin. The cream was applied under an occlusive dressing and left for $\mathbf{6 0}$ minutes before the adhesions were separated with a probe and a gauze swab. The procedure was completely pain free in 32 boys. One boy had to undergo a repeated procedure because he failed to follow the advice regularly to retract his foreskin in the three weeks after the procedure. Only one boy had to undergo circumcision later because of fibrous phimosis.

In many boys referred for circumcision separation of preputial adhesions is all that is needed, and the use of this local anaesthetic technique avoids the need for general anaesthesia.
\end{abstract}

\section{Introduction}

Non-retractability of the foreskin has has been a common pretext for circumcision. A non-retractable prepuce is not, however, synonymous with phimosis and it should not be used as an excuse for "lopping off an innocent and useful appendage." It has been claimed that the difference between intercourse with a circumcised and an uncircumcised penis is "the difference between slipping the foot into a sock that has been rolled up and one that is held open at the top." Bokai, in 1860, was the first to draw attention to the physiological adherence of the foreskin.

In 1927 Hamilton and Middleton reported from this hospital an investigation into phimosis and dysuria in infancy and concluded that circumcision was carried out too frequently. ${ }^{+}$In many cases separation of adhesions is all that is required. Deibert showed in 1933 that separation of the prepuce in the human penis is due to keratinisation of the subpreputial epithelium, a process not complete at birth but accomplished during early childhood." Apart from religious or tribal reasons there are few indications for circumcision, and its incidence is declining. ${ }^{\top} \mathrm{A}$ fibrous phimosis with scarring undoubtedly necessitates surgery, even in other species. ${ }^{x}$ Balanitis, however, is often quoted as an indication for circumcision, " in my opinion wrongly.

In cases of recurrent balanitis with a non-retractable foreskin separation of adhesions and subsequent preputial hygiene will prevent further attacks without the necessity of circumcision, which may itself predispose to meatitis and possible meatal stenosis." Preputial adhesions have commonly been separated under general anaesthetic, ${ }^{12}$ since separation in the outpatient department is traumatic to the child, even with the use of 5\% lignocaine cream. ${ }^{13}$ The introduction of Emla cream (eutectic mixture of local anaesthetics; Astra Pharmaceuticals), however, led me to investigate its value in allowing painless separation of preputial adhesions.

\section{Patients and methods}

Emla is a formula of lignocaine and prilocaine designed to alleviate the pain of venepuncture. ${ }^{1+}$ Unlike previously available topical preparations, it penetrates intact skin to produce intradermal anaesthesia. It not only reduces the pain of venepuncture in children but also makes the procedure easier. ${ }^{15}$ It has been evaluated in a variety of other indications, in particular split skin grafting and minor skin operations. "1 It must be applied under an occlusive dressing at least 60 minutes before the procedure.

The procedure is as follows. The child first empties his bladder. He then lies on a couch with his parent at the head end for reassurance. The boy is told that some "magic cream" is going to be applied to his penis and warned that it may feel cold. The foreskin is drawn forward over the small open end of the tube of cream and held closely applied with one hand, while the other squeezes a generous quantity (at least half the tube) under the foreskin. The foreskin is then held firmly between thumb and forefinger to prevent any cream from escaping. Any excess is carefully removed with a gauze swab, and a $3 \mathrm{M}$ Tegaderm dressing (supplied with the cream) is applied, the printed paper having 
TABLE I-Reasons for referral for circumcision in 39 boys treated by separation of adhesion

\begin{tabular}{lr}
\hline Reason for referral & No \\
\hline Recurrent balanitis & 13 \\
Phimosis & 10 \\
"For circumcision" & 6 \\
Ballooning on micturition & 4 \\
Adhesions & 4 \\
Lump on penis & 1 \\
Long redundant foreskin & 1 \\
\hline
\end{tabular}

Lump on penis

Long redundant foreski been removed to expose the adhesive surface. The dressing is applied with the backing paper in situ. This enables it to be folded in half over the penis, the sides of the dressing being squeezed together to ensure that a large quantity of the cream is retained in and around the prepuce. The child is then allowed to play for an hour.

The dressing is easily removed an hour later and excess cream mopped away. The adhesions can then be separated with a probe or using a gauze swab. It is preferable to use the latter, at least to clear the coronal sulcus. Complete anaesthesia of the glans and prepuce enables the procedure to be completely pain free. In the vast majority of patients the anaesthesia includes the coronal sulcus. A few might feel slight discomfort at this site. The boy and his parents are shown how the foreskin is to be fully retracted to reveal the coronal sulcus. Petroleum jelly is applied liberally to prevent readhesion. The boy and his parents are then advised to retract the foreskin fully and apply petroleum jelly at bathtime daily for seven days, followed by a week of simple retraction in the bath. The patient is reviewed at two weeks and if the treatment has been successful then advice about normal preputial hygiene is given and he is discharged.

So far 39 boys with preputial adhesions have been treated. The reasons for their referral to the clinic by their general practitioners are shown in table I. In each case the method was explained to the parents and their consent obtained.

\section{Results}

None of the 39 boys had a retractable foreskin. Their ages ranged from 2-12 years (table II). The procedure was completely pain free in 32 cases. Seven had mild

TABLE II-Age distribution of 39 boys referred for circumcision and treated by separation of adhesions

\begin{tabular}{lllllllllllll}
\hline Age (years): & 1 & 2 & 3 & 4 & 5 & 6 & 7 & 8 & 9 & 10 & 11 & 12 \\
\hline No & 0 & 1 & 9 & 4 & 9 & 3 & 4 & 3 & 3 & 2 & 0 & 1
\end{tabular}

discomfort, particularly on separation of the coronal component of the adhesions. Only one boy shed any tears. In most the complete anaesthesia achieved instilled great confidence.

One $31 / 2$ year old child returned to the accident and emergency department with paraphimosis. This was reduced, and, surprisingly, at review at two weeks his foreskin was lax and easily retractable. The parents of another child, the 4 year old who had cried at the initial procedure, reported great difficulty in retracting the foreskin. At the two week review the boy remained very frightened and at three months he had scarring and a fibrous phimosis necessitated circumcision. Nevertheless, three other patients who had had slight splitting and bleeding from a tight constrictive band at the initial procedure had a freely retractable unconstricted foreskin at two weeks. Recurrent dense adhesions in one boy, due to failure of retraction at home, were successfully separated by repeating the procedure. One mother found the method so successful on her 7 year old son that she brought his 5 and 9 year old brothers to the follow up clinic requesting the same technique.

No patient showed any sign of toxicity, although plasma concentrations of lignocaine and prilocaine were not measured. Studies have shown that even in children aged under 1 year (in whom the use of the lignocaine-prilocaine cream is not recommended) the application of a full $2 \mathrm{~g}$ of cream over a wide area of skin for four hours leads to a maximum plasma concentration of $149 \mu \mathrm{g} / \mathrm{l}$, far below the toxic concentration
(5000-6000 $\mu \mathrm{g} / \mathrm{l}$ (Rodgers B, Astra Pharmaceuticals, personal communication).

\section{Discussion}

General anaesthesia is not without risk (however small) and if it can be avoided for a simple procedure such as separation of preputial adhesions then that is an advantage. If circumcision can also be prevented that is a further bonus. Many doctors, of course, advocate neonatal circumcision without the need for anaesthesia and believe that this prevents later foreskin problems. There are, none the less, still risks in neonatal circumcision. ${ }^{17}$ The technique described here has proved to be effective, simple, and cheap-the cost of one tube of lignocaine-prilocaine cream (around £2) compared with the cost of day case surgery.

The infrequent true fibrous phimosis is one of the few medical indications for circumcision. Separation of adhesions is not, however, to be advocated for all other cases referred for possible circumcision on medical grounds. Separation should be rarely be required under the age of 3 years. The 2 year old included in this series had had ballooning on micturition and recurrent balanitis. Careful hygiene was first advocated but he returned three months later having had two further episodes of balanitis. Separation of adhesions should also prove unnecessary in many cases of a nonretractable foreskin where the simple technique advocated in 1950 by Sir James Spence to assess the foreskin will suffice ${ }^{18}$ : "Retract the prepuce and you will see a pinpoint opening, but draw it forward and you see a channel wide enough for all the purposes for which the infant needs the organ at that early age. What looks like a pinpoint opening at 7 months will become a wide channel of communication at 17 years."

In symptomatic cases this method of freeing the adhesions can prove worthwhile. It enables one to discuss preputial hygiene with the child, apparently a procedure that is often not performed. ${ }^{19}$ It should be something that is discussed at school medical examinations. ${ }^{20}$ Circumcision is all too frequently performed without good reason: it is rarely required.

1 Morgan WKC. The rape of the phallus. $7 A M A$ 1965;193:223-4.

2 Anonymous. Should baby be circumcised? The Widdicombe File. Lancel 1953;ii:337-8.

3 Bokai J. A fityma (preputium) sejtes adatapadasa a makko\% gyermakelnel. Orv Hetil !860;4:583-7.

4 Hamilton AJC, Middleton DS. Phimosis and dysuria in infancy. A clinical investigation. Lancel 1927; ;i:639-46.

5 Deibert GA. The separation of the prepuce in the human penis. Anat Rec 1933;54:387-93.

6 Gairdner D. The fate of the foreskin. Br Med $\mathcal{J}$ 1949;ii:1433-7.

7 Wisewell TE, Enzenauer RW, Cornish JD, et al. Declining frequency of circumcision: Implications for changes in the absolute incidence and male to female sex ratio of urinary tract infections in early infancy. Pediutrics female sex ratio of
$1987 ; 79: 338-42$.

8 Walker DF. Causes of copulatory failure in beef bulls. Mod Vet Pract 1984;65:252-6

9 Robarts FH. Penis and prepuce. In: Mason Brown JJ, ed. Surgeny of childhood. London: Edward Arnold, 1962:1159-81.

10 Stenram A, Malmfors G, Okmian L. Circumcision for phimosis: a follow up study. Scand J Urol Nephrol 1986;20:84-92.

11 Anderson GF, Smey P. Current concepts in the management of common urologic problems in infants and children. Pediatr Clin North Am 1985;32:1133-47.

12 Cooper GB, Thomson GJL, Raine PAM. Therapeutic retraction of the foreskin in childhood. Br Med $\mathcal{J}$ 1983;286:186-7.

13 Griffiths DM, Freeman NV. Non-surgical separation of preputial adhesions. Lancel 1984;2:344-5.

14 Eversh, Von Dardel O, Juhlin L, et al. Dermal effects of composition based on the eutectic nature of lignocaine and prilocaine. Br J Anuesth 1985;57: the eutectic

15 Hallen B, Uppfeldt A. Does lignocaine-prilociaine cream permit painfrec insertion of IV catheters in children? Anesthesiologv 1982:57:340-2.

16 Juhlin L, Evers H, Broberg F. A lidocaine-prilocaine cream for superficial skin surgery and painful lesions. Acta Derm Venereol (Siockh) 1980;60:5+4-6.

17 Editorial. The case against neonatal circumcision. Br Med J 1979;i:1163-4.

18 Spence on circumcision. Lancet 1964;ii:902.

19 Osborn LM, Metcalf TJ, Mariani EM. Hygienic care in uncircumcised infants. Pediatrics 1981;67:365-7.

20 Kalcev B. Circumcision and personal hygiene in school boys. The Med Officer 1964;122:171-3.

(Accepled 25 Mav 1987) 